\title{
Albanon
}

Revistë kulturore

\section{Vlerat e Bibliotekës Publike Qemal Baholli}

Manjola Hatellari

Qyteti i Elbasanit është qytet me tradita të lashta kulturore e arsimore. Historia e këtij qyteti dëshmon ndër të tjera dhe për përpjekjet e gjata shekullore për kulturë e arsim, për ruajtjen e gjuhës amtare e identitetin kombëtar, për përparimin e vendit. Përpjekjet për shkrimin e shqipes në krahinën e Elbasanit kanë filluar në shekujt XVII-XVIII. Këto përpjekje lidhen me emrat e Theodhor Bogomilit, Dhaskal Todrit, Kostandin Kristoforidhit etj. Shpikja e shkrimit lindi nevojën për të ruajtur ato që shkruheshin, pra lindi idenë e krijimit të bibliotekave për ruajtjen dhe grumbullimin e këtyre shkrimeve. Këta gjuhëtarë si dhe shoqëritë patriotike të krijuara nga vitet 1908-1909 kishin bibliotekat e tyre. Shkolla Normale e themeluar në vitin 1909 kishte bibliotekën e saj të krijuar nga vetë mësuesit apo nxënësit e shkollës.

Të gjitha këto përpjekje për dije e kulturë të elbasanasve u kurorëzuan me aktin fisnik të familjes Baholli, që ngriti bibliotekën të cilën e kemi dhe sot pas 84 vjetësh. Në këtë 84-vjetor të saj ajo radhitet ndër bibliotekat e pasura të Shqipërisë e njohur për:

1. antikuarin,

2. orientalistikën,

3. vlerat e botimeve të vjetra e të reja, në formë libri si dhe

4. periodikun që ka në fondin e saj.

Një vend të rëndësishëm zënë botimet e viteve 1500-1800 me karakter historik, gjeografik e letrar.

Ndër vlerat që ka biblioteka, së pari do të doja të përmendja veprat e humanistëve të shquar shqiptarë, si Marin Barleti me "Historinë e 
Skënderbeut", Pjetër Bogdanin me "Çetën e Profetëve" për më tepër Pjetër Budin me "Doktrinën e Krishterë" të cilën ne e kemi botim të vitit 1664. Ky libër është botimi me datim më të hershëm në gjuhën shqipe që ndodhet në bibliotekën tonë. Këto vepra përbëjnë vlera madhore të pasurisë sonë kulturore kombëtare popullore.

Nëfondin e antikuarit një interes të veçantë studimi kanë librat me të dhënat dhe informacionet për ilirët, të cilat përbëjnë burime njohëse për historinë e lashtë të popullit shqiptar. Këto libra janë të autorëve apo historianëve të shquar të kohës. Ndër to mund të permendim: Aleksandrin Apiani me veprën "De Bellis Civilibvs Romanorum" në gjuhën latine, në shqip "Luftrat iliro-romake". Faqe të tëra në libër i kushtohen Ilirisë si dhe mbretit Agron. Përmenden dhe qytetet Epidamni (Durrësi sot), Apollonia etj. Ky libër është botim i vitit 1526, më i vjetri që ndodhet në bibliotekën tonë. Vazhdojmë më tej Tit Livi, një historian latin, i cili në librat e tij shkruan për Ilirinë dhe mbretin Gent. Paulo Giovio, një tjetër historian i lashtë që ka shkruar për ilirët si dhe për Pirron e Epirit, apo Straboini e shumë të tjerë.

Ndër botime të tjera me vlerë, të këtij fondi, janë librat me karakter historik të historianëve të kohës, ku trajtohet figura e Skënderbeut, heroit tonë legjendar, luftrat e tij kundër Perandorisë Turke duke e quajtur apo cilësuar "simbol i qëndresës turke". Ndër këto historianë mund të përmendim Francesko Sansovino, Dhimitër Franko, Andrea Cambini, Andre Thevet, Lazaro Soranzo, historiani francez Jaqves Lavardin i cili e quan Skënderbeun Mbret të Shqipërisë apo historiani grek Nikolas Chalcondili e shumë të tjerë. Në këto libra, krahas figurës së Skënderbeut trajtohet dhe historia e Turqisë, por ka dhe të dhëna për historinë e Shqipërisë.

Vlera njohëse për historinë tonë paraqesin edhe librat e udhëtarëve dhe historianëve të ndryshëm europianë si Piccolomini apo kronikanëve osmanë si Evlija Çelebiu etj.

Në fondin tonë me vlera, për studime, hulumtime në fusha e degë të shkencave, gjenden veprat me karakter gjeografik siç është ajo me titull "Hyrje në gjeografinë e përgjithshme sa e vjetër dhe e re" në latinisht nga gjeografi dhe humanisti i famshëm Philipp Cluveri, botim i vitit 1659. në këtë libër faqe të tëra i dedikohen qyteteve si Shkodra, Vlora, Dyrrahu Ulqini dhe Apollonia. Një libër tjetër është dhe libri "Gjeografia universale e botës" i Abbevil Duval i vitit 1682, ku përmenden qytetet e Shqipërisë si Valona, Scutari etj. 


\section{Albanon}

\section{Revistë kulturore}

Kemi veprat me karakter gjubësor, të cilat trajtojnë çështje të gjuhësisë shqiptare si nga autorë të huaj ashtu dhe vendas. Ndër të huajt mund të përmendim Franz Bopi, Gustav Majer, Gorg von Hahn etj. ndërsa nga ato vendas kemi Naun Veqilharxhin, Kostandin Kristoforidhin, Aleksandër Xhuvanin, Eqerem Çabej, Mahir Domin e deri tek gjuhëtarët e sotëm. Do doja të veçoja këtu veprat e Kristoforidhit ku mund të permendim: botimet e dy Abetareve ne gegërisht dhe toskërisht përkatësisht të viteve $1867 \mathrm{e}$ 1872, "Gramatika" botim i vitit 1882 apo "Fjalori i gjuhës shqipe" botim i vitit 1904 të cilat kanë vlera të mëdha për gjuhën shqipe.

Vlerë përbëjnë edhe veprat me karakter folklorik, etnografik. Kemi veprën e Thimi Mitkos apo të Zef Jubanit të cilët hodhën themelet e folkloristikës shqiptare, vlerë për ne në këtë fushë janë dhe vëllimet e plota "Visaret e Kombit"

Ndër veprat me karakter etnografik mund të përmendim veprën e Margaret Hasluck e më vonë të Qemal Haxhihasanit etj.

Ndër veprat me karakter letrar, të cilat kanë vlera njohëse në këtë fushë, do të veçoja fillimisht arbëreshët e Italisë si De Rada, A. Lorekio, Dhimitër Camarda etj.

De Rada me veprën e tij "Këngë të Milosaos" (1836) hodhi themelet e letërsisë romantike shqiptare. Veprën e tij "Parimet e estetikës" (1861) ne e kemi botimin e parë origjinal dhe kjo përbën një tjetër vlerë për bibliotekën tonë. Edhe revistën "Fiamuri $i$ Arbrit" që është një kontribut i madh i çështjes kombëtare e kemi koleksion. Jemi përpjekur sot duke pasur edhe ndihmë nga dashamirësit e librit dhe bibliotekës, nga ata që janë rritur duke mësuar dhe studiuar në këtë bibliotekë, të digjitojmë dhe reklamojmë vlerat e rralla të bibliotekës sonë në shërbim të komunitetit. Duke iu përgjigjur kërkesave të kohës, si dhe iniciativës së qeverisë së sotme për digjitimin e trashëgimisë kulturore ne themi se megjithëse nuk kemi aparate profesionale, kemi fillimet e një pune shumë të mirë në shërbim të studiuesve. Vlerë të madhe në këtë fushë kanë edhe veprat e rilindasve tanë dhe sidomos vëllezërit Frashëri (veprat e të cilëve janë ribotuar disa herë), veprat e Asdrenit, Çajupit e më vonë të Konicës, Fishtës, Koliqit, Camajt e deri tek shkrimtarët e sotëm si Kadareja etj.

Përsa i përket orientalistikës, ne kemi një sasi të konsiderueshme librash të Orientit. Ato kanë përmbajtje të ndryshme nga fushat e matematikës, mjeksisë, historisë, fesë etj. Këto libra janë në gjuhët orientale dhe janë me kapak lëkure. 
Një vlerë e madhe për bibliotekën tonë është dhe fondi i periodikut të vjetër ku përfshihen periodikët që nga viti 1883 me revistën "Fiamuri i Arbrit"- De Rada, "Albania"1897 - F. Konica, revista "Dituria" 1909 - L. Skëndo, gazeta "Liria" - Selanik L. Skëndo, "Dielli" - Boston 1909, Tomorri - 1910 L.Nosi, Drita 1911 - Manastir, "Përlindja e Shqipnisë" 1913-1914 gazeta e parë e shtetit shqiptar, gazetat lokale të Elbasanit e deri te shtypi i ditëve të sotme.

Të gjitha këto vlera ne i kemi në fondi albano-balkanologjik që është fondi më i rëndësishëm i bibliotekë sonë, i cili përmban thesare të trashëgimisë sonë kulturore dhe vjen gjithnjë duke u pasuruar. Në ditët e sotme historianët, gjuhëtarët, studiuesit e ndryshëm nuk reshtin së shkruari për çështjen shqiptare. Vlerë të madhe kanë dhe përkthimet që i bëhen veprave të studiuesve dhe albanologëve të kohës së sotme, si dhe të viteve të mëparshme. Siç janë p.sh. përkthimet dhe ribotimet e Franz Babingerit, Evlija Çelebiut, Edith Durham e shumë studiuesve të tjerë. Këta studiues kanë shkruar dhe për qytetin tonë. Franz Babinger ka shkruar një libërth për kalanë e Elbasanit, botim i vitit 1931. Ky libër si dhe shumë të tjerë kanë vlera njohëse dhe krenarie, kur shikon të shkruhet për qytetin tënd nga studius të huaj.

Për të gjitha këto vepra me vlerë, ne kemi hartuar një bibliografi modeste me titull "Bibliografi e botimeve 1500-1800" për t'i ardhur në ndihmë lexuesve që kanë interesa në punën e tyre studimore. Kjo domosdoshëri e njohjes së botës mundësisht që nga zanafilla i tundon studiuesit e fushave të ndryshme të hulumtojnë dhe studimet e tyre të ecin paralelisht me jetën njerëzore duke i kultivuar vazhdimisht në kohë. Në ditët në vijim, kjo bibliografi do të pasohet nga një vëllim tjetër që do të pasqyrojë botimet pas vitit 1800 .

Ndër vlerat e bibliotekës sonë nuk mund të lija pa përmendur edhe literaturën tekniko-shkencore në gjuhë të huaj dhe shqip. Ky fond librash i ka ardhur në ndihmë shumë specialistëve dhe studiuesve të fushave të ndryshme të shkencës të komunitetit tonë dhe më gjerë.

Ky ishte pak a shumë një vështrim i përgjithshëm i vlerave të bibliotekës dhe detyra jonë sot është ta mirëmbajmë këtë fond për t'ia transmetuar gjeneratave të reja këto vlera të rralla të trashëgimisë sonë kulturore. Duke studiuar mirë të kaluarën mund të ecësh i sigurt drejt së ardhmes.

\section{Më poshtë po sjellim listën e librave që mbajnë vulën e Lef Nosit në bibliotekën e Elbasanit}

Lef Nosi (1877-1945) patriot, arkivist, folklorist, etnograf, numizmat, arkeolog e politikan shqiptar. Njihet si babai i filatelisë shqiptare, personalitet 


\section{Albanon}

\section{Revistë kulturore}

me interesa të gjera kulturore. Lef Nosi është një nga intelektualët që ka kontribuar në pasurimin e bibliotekës së Elbasanit, jo për nga sasia, por nga vlerat që kanë ata libra në historinë e vendit. Nga përmbajtja e librave që ai ka përzgjedhur kudo ku ka shëtitur nëpër botë, shohim dashurinë që ka për vendin tonë, sepse të gjitha librat flasin për Shqipërinë, në të gjitha aspektet; ekonomike, gjeografike, historike etj.

Një vlerë më vete për bibliotekën tonë është edhe periodiku, po nga fondi i Lef Nosit. (si p.sh. Albania e Konicës, Dituria e L. Skëndos, Dielli i Bostonit etj.)

Librat e fondit të Lef Nosit në bibliotekë, klasifikohen sipas degës së shkencës, përmes numrave nga 0-9:

0 - Dituria në përgjithësi

1 - Filozofia

$2-$ Feja

3 - Shkencat shoqërore

4 - vend vacant (dikur klasifikohej gjuhësia, por tani përmblidhet te numri 8)

5 - Shkencat ekzakte

6 - Shkencat e aplikuara

7 - Arti, sporti dhe zeje të ndryshme

8 - Shkencat filozofike dhe letërsia

9 - Historia, gjeografia dhe biografia

Shembull: libri i parë me numrin Scanderbeg (Georges Castrata) O P 56, tregon se është i klasifikuar te librat e diturisë në përgjithësi, $\boldsymbol{P}$ është iniciali i autorit dhe 56 është pozicioni i librit në fondin e bibliotekës.

Këtu bashkangjitur kemi listën e librave që mbajnë vulën e bibliotekës personale të patriotit dhe intelektualit të vërtetë Lef Nos, në bibliotekën e Ebasanit, "Q. Baholli”.

\begin{tabular}{|l|c|}
\hline Titulli & Degët e shkencës \\
\hline Scanderbeg(Georges Castrata) & OP 56 \\
\hline Bibliographie Balkanique 1920-1930 & 0S29 \\
\hline Bibliographie Balkanique 1931-1932 & 1 S29 \\
\hline Vocabulario italiano-epirotico & 4 C12 \\
\hline
\end{tabular}




\begin{tabular}{|c|c|}
\hline Titulli & Degët e shkencës \\
\hline Almanacco italo-albanese $1940=X V I I I$ & $08 A 59$ \\
\hline Principll di estetica & $1 D 29$ \\
\hline Le Consuetudini guridiche dell'albania & $39 V 68$ \\
\hline Albanie ein Hilferuf & 39 A 54 \\
\hline The ëomen of turkey and their folk-lore & 39 G 21 \\
\hline Kanget kombetare permbledhur prej L.Nosi & $39 N 85$ \\
\hline Contes populaires Serbes & $398 C 73$ \\
\hline Schriften der Balkankommission & $398 \mathrm{~L} 20$ \\
\hline Contes populaires Grecs & $398 \mathrm{~L} 41$ \\
\hline Albanesische studien & 398 M 66 \\
\hline Jugoslav popular ballads & $398 S 95$ \\
\hline Les Manuscrits Grecs & $4 B 31$ \\
\hline Stud II Linguistici & $4 B 60$ \\
\hline Les langues de l'europe Moderne & $4 S 30$ \\
\hline Balkan-archiv & $4 \mathrm{~V} 42(1)$ \\
\hline Balkan-archiv & $V 42(2)$ \\
\hline Balkan-archiv & $4 V 42(3)$ \\
\hline 22- Die Albanisischen und slavischen Schriften & 491.983 G 33 \\
\hline 23- Indogermonifche forldjnngen & $491.983 \mathrm{~J} 72$ \\
\hline $\begin{array}{l}\text { 24- Zur Erforschung der albanischen Mundarty vor Borgo Erizzo in } \\
\text { Dalmazien }\end{array}$ & $491.983 \mathrm{~J} 73$ \\
\hline $\begin{array}{l}\text { 25- Linguistisch-kulturhistorische unteruchungen aus dem Bereiche } \\
\text { des Albanischen }\end{array}$ & $491.983 \mathrm{~J} 72$ \\
\hline 26- Gramatica della Lingua Albanese & $491.983 \mathrm{~J} 21$ \\
\hline $\begin{array}{l}\text { 27- Conferenze su l'antichita della Lingue albanese e gramatica della } \\
\text { medesima }\end{array}$ & 491.983 D 29 \\
\hline 28- Studi Linguistici albanesi (Marco la Piana) & 491.983 L 11/1 \\
\hline $\begin{array}{l}\text { 29-Studii filologici svolti con la lingua pelasco-albanese (Stanislao } \\
\text { Marchiano) }\end{array}$ & 498.983 M 32 \\
\hline 30- La campagna di durazzo fra cesare e pompeo (G.Veith) & $93 / 99 \mathrm{~V} 42$ \\
\hline 31- La dalmatie, I'Italie et I'unite yougoslave (1797-1917) & $93 / 99 \mathrm{~V} 83$ \\
\hline 32- The cradle of the ëar & $93 / 99 \mathrm{~V} 86$ \\
\hline 33- La Turquie et ses voisins & $93 / 99 \mathrm{~V} 86$ \\
\hline 34- The balkans from ëithin Reginald ëyon & $93 / 99 \mathrm{~V} 99$ \\
\hline
\end{tabular}




\section{Albanon}

\section{Revistë kulturore}

\begin{tabular}{|c|c|}
\hline Titulli & Degët e shkencës \\
\hline 35- Albania and her neighbours & 949.65 A 54 \\
\hline 36- Acta et Diplomata res Albaniae mediae Aetatis & 949.65 A $19 / 1$ \\
\hline 37- Acta et Diplomata res Albaniae mediae Aetatis & 949.65 A $19 / 2$ \\
\hline 38- Die Grundung von Elbasan von Franz Babinger & 949.65 B 12 \\
\hline 39- Studi speciali albanesi 1 & 949.65 B 21/1 \\
\hline 40- Studi speciali albanesi 2 & 949.65 B 21/2 \\
\hline 41- La corona albanese & 949.65 B 21 \\
\hline 42- L'albanie et Napoleon & 949.65 B 78 \\
\hline 43- Romeni de Albania & 949.65 B \\
\hline 44- Riflessi e visioni della Grande guerra in Albania & $949.65 C 75$ \\
\hline 45- Saggio di un regesto storico dell'Albania & $949.65 C 75$ \\
\hline 46- II patriarcato greco & $949.65 C 71$ \\
\hline 47- L'albanie & $949.65 C 95$ \\
\hline 48- Albania post and present & $949.65 C 35$ \\
\hline 49- Memoriet e mija & 949.65 D 64 \\
\hline 50- L'avenir de l'Albanie & 949.65 D 42 \\
\hline $\begin{array}{l}\text { 51- L'evolution de la Neutralite et les Problemes d'actualite qui s'y } \\
\text { Rattachent }\end{array}$ & 949.65 D 42 \\
\hline 52- L'albanie independante et l'empire Khalifal ottoman & 949.65 D 86 \\
\hline 53- The strugglefar scutari & 949.65 D 90 \\
\hline 54- Albania & $91 \mathrm{M} 33$ \\
\hline 55- In Albaniens Bergen & $91 \mathrm{M} 33$ \\
\hline 56- Karl Itten die reife burch Albanien & 91096 \\
\hline 57 - Voyage de la grece & $91 P 89 / 3$ \\
\hline 58 -Voyage de la grece & $91 P 89 / 4$ \\
\hline 59-Voyage de la grece & $91 P 89 / 5$ \\
\hline 60 -Voyage de la grece & 91 P $89 / 6$ \\
\hline 61- Dekapente Hmepai eis thn Albanian & $91 P 27$ \\
\hline 62-Voyage en moree a constantinople et en Albanie & $91 P 89 / 2$ \\
\hline 63-Voyage en moree a constantinople et en Albanie & $91 P 89 / 3$ \\
\hline 64- Through Macedonia to the albanian lakes & $91 \mathrm{~V} 21$ \\
\hline 65- Ëashed by four seas & $91 \mathrm{~V} 86$ \\
\hline 66-Vie d'ali pocha & $92 B 34$ \\
\hline
\end{tabular}




\begin{tabular}{|c|c|}
\hline Titulli & Degët e shkencës \\
\hline 67-The life of Ali Pasha & $92 \mathrm{D} 28$ \\
\hline 68- Travels in epirus,albania,macedonia and thessaly & $91 P 89$ \\
\hline 69- Gli Albanesi e la Questione Balkanica & $949.65 S 30$ \\
\hline 70-The sorroës of Epirus & $91 P 97$ \\
\hline 71- Nouvelle geographie universelle & $91 \mathrm{R} 37$ \\
\hline 72- Einie Reise durch die hochlandergaue oberalbaniens & 91591 \\
\hline 73- L'avvenire dell'albania & $91 \mathrm{~T} 19$ \\
\hline 74- Tubinger geographische und geologische Abhandlungen, Reihe 2 & $91 \cup 64$ \\
\hline 75- Studi speciali albanesi Antonio Baldacci & 949.65 B 21/1 \\
\hline 76- Studi speciali albanesi Antonio Baldacci & 949.65 B 21/2 \\
\hline 77- Travels in Greece and Albania & $908 \mathrm{H} 97 / 1$ \\
\hline 78- Travels in Greece and Albania & $908 \mathrm{H} 97 / 2$ \\
\hline 79- Travels in sicily greece and albania & $908 \mathrm{H} 97 / 1$ \\
\hline 80 - The peaks of shala & $908 \mathrm{~L} 21$ \\
\hline 81- The servian people & $908 \mathrm{~L} \mathrm{33/2}$ \\
\hline 82- Le terre albanese redente I Kossovo & $908 \mid 36 / 1$ \\
\hline $\begin{array}{l}\text { 83- Albanien Bauten,trachten und gerate nord albaniens von dr.Franz } \\
\text { Boron Nopcsa }\end{array}$ & $908 \mathrm{~N} 82$ \\
\hline 84- Albania the foundling state of europe & 908 P 38 \\
\hline 85- Dëars door Albanie S.A.Reitsma & $908 R 46$ \\
\hline 86- King Zog's Albania & $908 S 98$ \\
\hline 87- Memoirs on the ionian islands & $908 V 32$ \\
\hline 88- The tale of a tour in Macedonie & $91 \mathrm{~A} 13$ \\
\hline $\begin{array}{l}\text { 89- Localita, chiese,fiumi,montietoponimi varu di un'antica carta } \\
\text { dell'Albania Settentrianale }\end{array}$ & 91 A 79 \\
\hline 90- Excursions in albasnia & 91 B 46 \\
\hline 91- A ëinter in Albania & 91 B 85 \\
\hline 92- La Grece continentale et la moree & $91 \mathrm{~B} 88$ \\
\hline 93- Travels in Albania and other provinces of turkey in 1809 and 1810 & $91 \mathrm{~B} 85 / 2$ \\
\hline 94- Im turkischen kriegslager durch Albanien & $91 \mathrm{~J} 13$ \\
\hline 95- Skutari un die Nord albanische kustenebene & 91163 \\
\hline 96- Durch Albaniens Schluchten & $91 \mathrm{~K} 31$ \\
\hline 97- Journals of a landscope painter in albania & $91 \mathrm{~L} 36$ \\
\hline
\end{tabular}




\section{Albanon}

Revistë kulturore

\begin{tabular}{|c|c|}
\hline Titulli & Degët e shkencës \\
\hline 98- L'albania in grigio verde & $91 C 36$ \\
\hline 99- Visits to monasteries in the levant & $91(96$ \\
\hline 100-Souvenirs de la haute-albanie & $91 D 33$ \\
\hline 101- Pictures from the Balkans & $91 \mathrm{~F} 84$ \\
\hline 102- Montagne d'albanie & $91 \mathrm{G} 46$ \\
\hline 103- Assestamento e rinascita dell'Albania & $91 \mathrm{G} 51$ \\
\hline 104- Histoire et description de la haute albanie ou guegorie & $91 \mathrm{H} 39$ \\
\hline 105- Travels in the ionian isles albania,thessaly, macedonia & $91 \mathrm{H} 80 / 2$ \\
\hline 106- Tende all'alba & $8 F 78$ \\
\hline 107- Libres! (Edmond Gonginet) & $8 \mathrm{G} 64$ \\
\hline 108- The captain of the Janizaries & $8 \mathrm{~L} 92$ \\
\hline 109-Scanderbeg or, love and liberty a trgedy & $8 \mathrm{~V} 61$ \\
\hline 110- Anno Eroico & $8 \mathrm{~V} 71$ \\
\hline 111- Giovanni Uniade & 891.983 D 29 \\
\hline 112-Albania 1 & 908 A 54/1 \\
\hline 113- Les pays d'albanie et leur historie & 908 G 46 \\
\hline 114- L'albania & $908 \mathrm{G} 16$ \\
\hline 115- Oberalbanien und seine liga & 908 G 65 \\
\hline 116- L’Albania & 908 B 21 \\
\hline 117- Annuario del Regno di albania & 908 A 67 \\
\hline 118- Cieci giorni al montenegro (M.Cagni) & $908 C 15$ \\
\hline 119-Albania the master key to the near east & $908 \mathrm{D} 17$ \\
\hline 120-The Balkan peninsula & $908 \mathrm{~F} 82$ \\
\hline 121 - Zygmunt Milkoëski & 93/99 B 37 \\
\hline 122 - Il potere marttimo nella grande guerra & 93/99 B 45 \\
\hline 123 - Voyage du jeune anacharsis en grece (Tome Premier) & 93/99 B 27/1 \\
\hline 124 - Voyage du jeune anacharsis en grece (Tome Premier) & 93/99 B 27/2 \\
\hline 125 - Voyage du jeune anacharsis en grece (Tome Premier) & $93 / 99$ B 27/3 \\
\hline 126 - Voyage du jeune anacharsis en grece (Tome Premier) & $93 / 99$ B $27 / 4$ \\
\hline 127 - Voyage du jeune anacharsis en grece (Tome Premier) & 93/99 B 27/5 \\
\hline 128 - Voyage du jeune anacharsis en grece (Tome Premier) & 93/99 B 27/6 \\
\hline 129 - Voyage du jeune anacharsis en grece (Tome Premier) & $93 / 99$ B 27/7 \\
\hline 130 - Alla quota 731 di monastero maurizio Bassi & $93 / 99$ В 29 \\
\hline
\end{tabular}




\begin{tabular}{|l|r|}
\hline Titulli & Degët e shkencës \\
\hline 131 - Grammatik albanefifchen sprache & 491.938 P 45 \\
\hline 132 - Regole grammaticali della lingua albanese & 491.983 R 89 \\
\hline 133 - Pubblicazione scientifico-tecniche (Fascicolo) & 55 Z 94 \\
\hline 134 - Relazione della commissione per la studio dell'albania 2 & 63 R 89 \\
\hline 135 - Per una ferrovia albano-macedone & 62 B 27 \\
\hline 136 - Relazione alle foreste nell'Albania settentrionale & 63 M 45 \\
\hline 137 - Il problema forestale Albanese & 63 M 70 \\
\hline 138 - Studio e proposte & 63 S 94 \\
\hline 139 - La guerra & $7 \mathrm{~L} \mathrm{11}$ \\
\hline 140 - Lule nga Fabian Barcata & 8 B 27 \\
\hline 141 - Saggi di letteratura bulgara antica Arturo Cronia & 8 C 90 \\
142 - Çelebi, Evlija “ Shqipmija para dy shekujsh” & 91 Ç 36 \\
\hline
\end{tabular}

